\title{
Synthesis, Characterisation and Antimicrobial Screening of Some Cyanoethylated Bioactive Azomethines and $\beta$-Lactams
}

\author{
Pradeep K Soni* and Anand K Halve \\ Department of Chemistry, Jiwaji University, India
}

*Corresponding author: Pradeep K. Soni, School of Studies in Chemistry, Jiwaji University, Gwalior, India- 474011

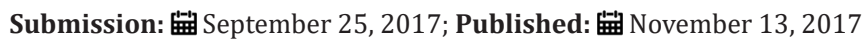

\begin{abstract}
A library of azomethines SB1-SB10 has been synthesized by the condensation of 3,3'-((4-formyl-3-methoxyphenyl)azanediyl)dipropanenitrile (C) with aniline, fluoro-, chloro- and bromo- anilines. Azomethines at the imine linkage on reaction with chloroacetylchloride and triethylamines in 1,4-dioxan afforded a series of novel $\beta$-lactams BL1-BL10. 3,3'-((4-formyl-3-methoxyphenyl)azanediyl) dipropanenitrile (C) was synthesized by cyanoethylation of the $\mathrm{m}$-anisidine followed by formylation in presence of $\mathrm{POCl}_{3}$ and DMF. All compounds were characterized by elemental analysis, FTIR and ${ }^{1}$ HNMR data and screened in-vitro for their activity against $S$. aureus, B. subtilis, P. vulgaris, E. coli, A. niger and A. fumigatus. Most of the compounds showed significant activity against microorganisms tested.
\end{abstract}

Keywords: ß-lactams; Azomethines; Tertiary-amino-benzaldehyde; Cyanoethylation; Antimicrobial activity

Abbreviations: RAND: Research and Development; Anti-MHV: Anti-Mouse Hepatitis Virus; HSV-1: Herpes Simplex Virus Type-1; AD-5: Adenovirus Type-5; DMSO: Dimethyl Sulfoxide; MIC: Minimum Inhibitory Concentration; DMF: Dimethyl Formamide; TMS: Tetramethyl Silane

\section{Introduction}

Pathogenic micro-organisms have been engaged in an evolutionary battle with the humans and animals since the dawn of time. Every time a new developed antimicrobial resistance is followed. This is posing a serious challenge to scientific community and greatest threat to human health. Antibiotic resistance has increased dramatically in the last few decades. Most of the antibiotics currently in use were discovered in the 'Golden era' of antibiotics. World Health Organization [1] has declared that "The world is moving towards a post-antibiotic era in which common infections will once again kill". By estimation of the RAND (Research and Development) Corporation 10 million people world-wide could die from resistant micro-organisms in 2050 which is more than from cancer. There is always need for the safer antibacterial agents and research efforts are going on for developing better and more effective antibacterial agents. Antimicrobial agents containing $\beta$-lactams has become an integral part of the chemotherapeutic arsenal available to today's medical practitioners. Azomethines and their derivatives has been a research subject [2] due to their pharmacological applications [3,4] and striking complex-metric behaviour. These properties allow them to play a pivotal role in various biological activities [5,6] viz. Anti-bacterial [7] antiviral [8], antifungal [9], anthelmintic [10], anti-amoebic [11], antiinflammatory [12], analgesic [13], anti-mouse hepatitis virus
(MHV) [14], inhibition of herpes simplex virus type-1 (HSV-1), adenovirus type-5 (AD-5) [15] anti-malarial [16] and herbicidal [17] activities. $\beta$-Lactams are well-known heterocyclic compounds among the organic and medicinal chemists. Biological activities of the famous antibiotics such as penicillin's, cephalosporins and carbapenems are attributed to the presence of $\beta$-lactam ring in them. Some other types of biological activity besides the antibacterial activity have been reported in compounds containing $\beta$-lactams ring [18]. Such biological activities include antimicrobial [19], anti-tubercular [20], carbonic anhydrase inhibitors [21], anticonvulsant [22], anti-inflammatory [23], anthelmintic [24] and hypoglycaemic activities [25]. The $\beta$-lactams also serve as synthase for biologically important classes of organic compounds [26]. We have also prepared some azomethines and $\beta$-lactams containing cyanoethyl groups previously displaying good antimicrobial activities [27]. Azomethines formed by 3,3'-((4-formyl phenyl) azanediyl)dipropanenitrile and their stable complexes with some metals have been reported by Arora et al. [28]. A new series of complexes of dioxo-uranium (IV) with the azomethines (E)-3,3'-((4((phenylimino)methyl)phenyl)azanediyl)dipropanenitrile derived from N-[(4-N'N-bis-(2'cyanoethyl aminobenzylideneamino] benzaldehyde and aniline were prepared by Arora et al. [29] It is well known that the introduction of fluorine atom into an organic 
molecule causes dramatic changes in its biological activity profile, mainly due to high electro negativity of fluorine, the strong carbonfluorine bond and increased solubility in lipids. Azomethines containing chloro and cyano groups display enhanced antibacterial activities [30]. It was thought worthwhile to incorporate cyanoethyl moiety and halogen groups to the $\beta$-lactam nucleus and study invitro their biological potential.

\section{Materials and Methods}

Melting points were determined in an open capillary tube and are uncorrected. The chemicals and solvents used were of laboratory grade and were purified further. Completion of the reaction was monitored by thin layer chromatography on pre-coated sheets of 25 DC alufolin Kieselgel $60 \mathrm{~F}_{254}$ silica gel $60 \mathrm{~F}_{254}$ (Merck) using UV-vis florescence analysis chamber for detection. FT-IR spectra were recorded in $\mathrm{KBr}$ on a Perkin-Elmer spectrophotometer-2. 1HNMR spectra were recorded in DMSO-d6 with an advanced spectrophotometer (Bruker) at $400-\mathrm{MHz}$ frequency using TMS as an internal standard. Elemental analyses were performed on a Perkin-Elmer-240, elemental analyzer. All the synthesized compounds were purified by re-crystallization in ethanol.

\section{Preparation of 3,3'-((4-formyl-3-methoxyphenyl) azanediyl)dipropanenitrile}

Cyanoethylation of m-anisidine; Formation of 3,3'-((3-methoxyphenyl) azanediyl) dipropanenitrile: A mixture of freshly distilled $\mathrm{m}$-anisidine $(0.1 \mathrm{~mol})$, acrylonitrile $(0.4 \mathrm{~mol})$ glacial acetic acid $(0.33 \mathrm{~mol})$ and freshly prepared cuprous chloride $(1.5 \mathrm{~g})$ were gently refluxed for twelve hours. The liquid mixture was cooled and poured with stirring into liquor ammonia $(100 \mathrm{ml})$ and mixture was left aside overnight. The solid formed was washed well with water till free from copper salts. The solid was filtered and re-crystallized from ethanol when 3,3'-((3-methoxyphenyl)azanediyl)dipropanenitrile was obtained as colourless needles.

Formylation of $3,3^{\prime}-((3-$-methoxyphenyl)azanediyl) dipropanenitrile; Formation of 3,3'-((4-formyl-3methoxyphenyl)azanediyl)dipropanenitrile(C): $\quad \mathrm{N}$ 'N-bis-2'cyanoethyl-m-anisidine $(0.04 \mathrm{~mol})$ was slowly added to a cooled mixture of phosphorous oxy-chloride $(0.04 \mathrm{~mol})$ and dimethyl formamide $(0.16 \mathrm{~mol})$ taken in a round bottomed flask provided with a mechanical stirrer and a reflux condenser carrying a calcium chloride guard tube. The contents were heated on a steam bath for three hours while the mixture was stirred. The dark mixture was cooled and poured over crushed ice and the solution neutralised with crystalline sodium acetate the content were set aside overnight; when the solid product separated out. It was filtered under suction, washed well with water and recrystallized from ethanol when the aldehyde (C) was obtained as light yellow needles. Elemental analysis data of 3,3'-((4-formyl-3-methoxyphenyl) azanediyl)dipropanenitrile (C): Molecular Formula; $\mathrm{C}_{14} \mathrm{H}_{15} \mathrm{~N}_{3} \mathrm{O}_{2}$, Yield 64.14\%, Elements; Required (Found \%): C 65.35(64.90), H 5.88(5.73), N 16.33(16.02). Spectral data; Groups (FT-IR absorption frequencies $\mathrm{cm}^{-1}$ in $\mathrm{KBr}$ ): $\mathrm{CHO}$ (1676.5), $\mathrm{N}-\mathrm{CH}_{2}$ (2249.1), $\mathrm{CH}_{2} \mathrm{CN}$
(2744.2) $\mathrm{OCH}_{3}$ (1716.5), $\mathrm{CH}(\mathrm{Ar})(2971.8) .1 \mathrm{H}$ NMR-Spectra in DMSO-d6: Protons signal groups ( $\delta \mathrm{ppm})$ : $3 \mathrm{HS} \mathrm{OCH} \mathrm{OCH}_{3}(3.828), 4 \mathrm{HT}$ $\mathrm{CH}_{2} \mathrm{CN}(2.795-2.829), 4 \mathrm{HT} \mathrm{CH}_{2} \mathrm{CH}_{2} \mathrm{CN}(3.814-3.848)$, 1HD $\mathrm{Ar}(6.996-$ 7.018), 1HS Ar(7.216), 1HD Ar(7.717-7.739), 1HS CHO (9.734).

\section{General procedure for the preparation of azomethines SB1-SB10}

Solution of an aldehyde (C) (0.0103 mol) and appropriate amine $(0.0103 \mathrm{~mol})$ in ethanol with $1-2$ drops of concentrated $\mathrm{H}_{2} \mathrm{SO}_{4}$, were refluxed over eight hours, mixture was cooled overnight and transferred into crushed ice with addition of 1-2 drops of concentrated sulphuric acid. After one hour precipitate was obtained by filtration and washing two times with distilled water, dried into air and re-crystallized with ethanol, azomethines obtained as yellow crystals. Elemental analysis of (Z)-3,3'-((4(((2-fluorophenyl)imino)methyl)-3-methoxy-phenyl)-azanediyl) dipropanenitrile (Azomethine-SB2): Molecular Formula; $\mathrm{C}_{20} \mathrm{H}_{19} \mathrm{FN}_{4} \mathrm{O}$, Yield 54.18\% Elements; Required (Found \%); C 68.56(68.26), H 5.47(5.36), N 15.99(15.42). Spectral data; Groups (FT-IR absorption frequencies $\mathrm{cm}^{-1}$ in $\mathrm{KBr}$ ): $\mathrm{C}=\mathrm{N}$ (1679.6), $\mathrm{N}-\mathrm{CH}_{2}-$ (2249.1), $\mathrm{CH}_{2}-\mathrm{CN}(2744.2), \mathrm{OCH}_{3}$ (1760.5), $\mathrm{CH}$ Ar (2973.6). ${ }^{1} \mathrm{H}$ NMRSpectra in DMSO-d6: Proton signal groups ( $\delta \mathrm{ppm}) 3 \mathrm{HS}$ OCH3 (3.801), 4HT $\mathrm{CH}_{2} \mathrm{CN}(2.781-2.816), 4 \mathrm{HT} \mathrm{CH}_{2} \mathrm{CH}_{2} \mathrm{CN}(3.795-3.829)$, 1HS Ar(6.752), 1HD Ar(6.758-6.822), 2HD Ar(7.628-7.650), 3HD (3) $\operatorname{Ar}(8.754-8.853), 1 \mathrm{H} \mathrm{CH}=\mathrm{N}(9.935)$.

\section{General procedure for the preparation of $\beta$-lactams BL1- BL10}

Table 1: Physical data of azomethines (SB1-SB10).

\begin{tabular}{|c|c|c|c|c|c|}
\hline S.No. & $\begin{array}{c}\text { Comp. } \\
\text { Name }\end{array}$ & $\mathbf{R}$ & m.p. ${ }^{\mathbf{0}} \mathbf{C}$ & $\begin{array}{c}\text { Yield } \\
\text { (\%) }\end{array}$ & $\begin{array}{c}\text { Molecular } \\
\text { formula }\end{array}$ \\
\hline 1. & SB1 & Aniline & 155 & 64.45 & $\mathrm{C}_{20} \mathrm{H}_{20} \mathrm{~N}_{4} \mathrm{O}$ \\
\hline 2. & SB2 & 2-Fluoroaniline & 142 & 54.18 & $\mathrm{C}_{20} \mathrm{H}_{19} \mathrm{FN}_{4} \mathrm{O}$ \\
\hline 3. & SB3 & 3-Fluoroaniline & 137 & 56.42 & $\mathrm{C}_{20} \mathrm{H}_{19} \mathrm{FN}_{4} \mathrm{O}$ \\
\hline 4. & SB4 & 4-Fluoroaniline & 182 & 54.86 & $\mathrm{C}_{20} \mathrm{H}_{19} \mathrm{FN}_{4} \mathrm{O}$ \\
\hline 5. & SB5 & 2-Chloroaniline & 134 & 64.91 & $\mathrm{C}_{20} \mathrm{H}_{19} \mathrm{ClN}_{4} \mathrm{O}$ \\
\hline 6. & SB6 & 3-Chloroaniline & 136 & 65.53 & $\mathrm{C}_{20} \mathrm{H}_{19} \mathrm{ClN}_{4} \mathrm{O}$ \\
\hline 7. & SB7 & 4-Chloroaniline & 125 & 45.74 & $\mathrm{C}_{20} \mathrm{H}_{19} \mathrm{ClN}_{4} \mathrm{O}$ \\
\hline 8. & SB8 & 2-Bromoaniline & 156 & 66.56 & $\mathrm{C}_{20} \mathrm{H}_{19} \mathrm{BrN}_{4} \mathrm{O}$ \\
\hline 9. & SB9 & 3-Bromoaniline & 143 & 67.23 & $\mathrm{C}_{20} \mathrm{H}_{19} \mathrm{BrN}_{4} \mathrm{O}$ \\
\hline 10. & SB10 & 4-Bromoaniline & 180 & 65.41 & $\mathrm{C}_{20} \mathrm{H}_{19} \mathrm{BrN}_{4} \mathrm{O}$ \\
\hline
\end{tabular}

A mixture of azomethines $(0.0047 \mathrm{~mol})$ and tri-ethylamine $(0.0047 \mathrm{~mol})$ was dissolved in 1,4 -dioxane $(50 \mathrm{~mL})$ with stirring and cooled. Chloroacetylchloride $(0.0047 \mathrm{~mol})$ was added drop wise within a period of 30 minutes. The reaction mixture was stirred further for $8-12$ hours at $50-70^{\circ} \mathrm{C}$. The reaction mixture was concentrated, cooled and poured into crushed ice and water, after one hour solid precipitate was filtered and washed 
with water and then air dried. The product thus obtained was re-crystallized using ethanol. $\beta$-lactams were obtained as dark coloured crystals. Elemental analysis data of 3-[\{4-[3-chloro1-(2-fluorophenyl)-4-oxoazetidin-2-yl]-3-methoxyphenyl\} (2-isocyanoethyl)amino]propanenitrile ( $\beta$-lactam BL2): Molecular Formula; $\mathrm{C}_{22} \mathrm{H}_{20} \mathrm{ClFN}_{4} \mathrm{O}_{2}$, Yield 63.31\%, Elements; Required (Found \%); C 61.90(60.36), H 4.72(4.26), N 13.12 (12.01). Spectral data; Groups (FT-IR absorption frequencies in $\mathrm{cm}^{-1} \mathrm{KBr}$ ): $\mathrm{C}=\mathrm{O}(1749.2)$,

Table 2: Physical data of $\beta$-lactams (BL1-BL10).

\begin{tabular}{|c|c|c|c|c|c|}
\hline S.No & Comp. Name & R & m.p. ${ }^{\mathbf{0}}$ & Yield \% & Molecular Formula \\
\hline 1. & BL1 & Aniline & 140 & 66.23 & $\mathrm{C}_{22} \mathrm{H}_{21} \mathrm{ClN}_{4} \mathrm{O}_{2}$ \\
\hline 2. & BL2 & 2-Fluoroaniline & 145 & 63.31 & $\mathrm{C}_{22} \mathrm{H}_{20} \mathrm{ClFN}_{4} \mathrm{O}_{2}$ \\
\hline 3. & BL3 & 3-Fluoroaniline & 132 & 59.25 & $\mathrm{C}_{22} \mathrm{H}_{20} \mathrm{ClFN}_{4} \mathrm{O}_{2}$ \\
\hline 4. & BL4 & 4-Fluoroaniline & 165 & 62.62 & $\mathrm{C}_{22} \mathrm{H}_{20} \mathrm{ClFN}_{4} \mathrm{O}_{2}$ \\
\hline 5. & BL5 & 2-Chloroaniline & 162 & 65.13 & $\mathrm{C}_{22} \mathrm{H}_{20} \mathrm{Cl}_{2} \mathrm{~N}_{4} \mathrm{O}_{2}$ \\
\hline 6. & BL6 & 3-Chloroaniline & 135 & 64.53 & $\mathrm{C}_{22} \mathrm{H}_{20} \mathrm{Cl}_{2} \mathrm{~N}_{4} \mathrm{O}_{2}$ \\
\hline 7. & BL7 & 4-Chloroaniline & 141 & 60.52 & $\mathrm{C}_{22} \mathrm{H}_{20} \mathrm{Cl}_{2} \mathrm{~N}_{4} \mathrm{O}_{2}$ \\
\hline 8. & BL8 & 2-Bromoaniline & 93 & 64.61 & $\mathrm{C}_{22} \mathrm{H}_{20} \mathrm{BrClN}_{4} \mathrm{O}_{2}$ \\
\hline 9. & BL9 & 3-Bromoaniline & 82 & 62.28 & $\mathrm{C}_{22} \mathrm{H}_{20} \mathrm{BrClN}_{4} \mathrm{O}_{2}$ \\
\hline 10. & BL10 & 4-Bromoaniline & 130 & 61.44 & $\mathrm{C}_{22} \mathrm{H}_{20} \mathrm{BrClN}_{4} \mathrm{O}_{2}$ \\
\hline
\end{tabular}

$\mathrm{OCH}_{3}$ (1605.2), $\mathrm{CH}_{2}-\mathrm{C}-\mathrm{CN}(2249.1), \mathrm{CH}_{2} \mathrm{CN}(2039.9)$, $\mathrm{CH}-\mathrm{Ar}(2981.7)$. ${ }^{1} \mathrm{H}$ NMR spectra in DMSO-d6: Protons signals (Groups) $(\delta \mathrm{ppm})$ 4HT $\mathrm{CH}_{2} \mathrm{CN}(2.810-2.844), \quad 4 \mathrm{HT} \quad \mathrm{CH}_{2} \mathrm{CH}_{2} \mathrm{CN}(3.829-3.864), \quad 3 \mathrm{HS}$ $\mathrm{OCH}_{3}$ (3.929), $1 \mathrm{HD} \mathrm{CH}$ of $\beta$-lactam Ring (5.232-5.253), $1 \mathrm{HD} \mathrm{CHCl}$ of $\beta$-lactam Ring (5.631-5.659), 1HS Ar(6.379), 1HD Ar(6.4796.483), 1HD Ar(7.531-7.553), 1HD Ar(8.689), 1HD Ar(8.747), 1HT $\operatorname{Ar}(8.884), 1$ HT $\operatorname{Ar}(8.921)$ (Table 1,2).

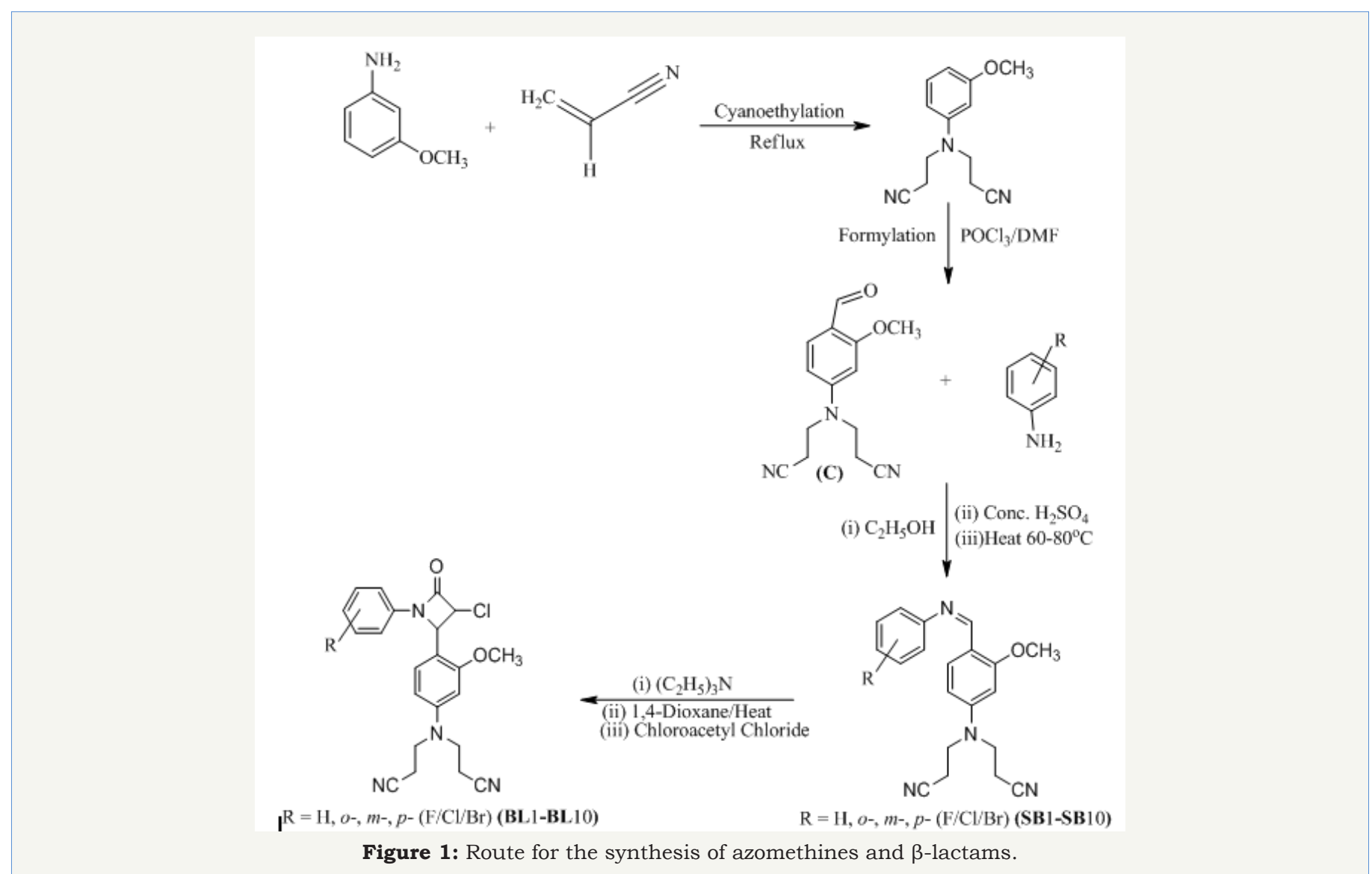




\section{Antimicrobial susceptibility testing}

All the synthesized azomethines SB1-SB10 and $\beta$-lactams BL1-BL10 were subjected to in-vitro antimicrobial susceptibility testing against Stayphylococcus aureus, Bacillus subtilis (Gram “+”ve) Proteus vulgaris, Escherichia coli (Gram "-"ve); bacterial and Aspergillus niger, Aspergillus fumigatus fungal strains in order to determine their efficacy and structure-activity relationship taking ampicillin as broad-spectrum antibacterial and fluconazole as an anti-fungal standard drugs. The antimicrobial activities of the synthesized compounds were studied by disc diffusion method. The serial dilution method was used to determine the minimum inhibitory concentration (MIC) of the synthesized compounds. DMSO was used as the negative control solvent for the compounds. Few colonies of organisms in 2-5mL nutrient Mueller-Hinton agar medium (for bacterial strains) and Sabourauds broth (for fungal strains) were grown for $2.5 \mathrm{~h}$. After the inoculums dried, $6 \mathrm{~mm}$ diameter wells were made in the agar plate with a sterile cork borer. The compounds were dissolved in DMF at concentration of $300 \mu \mathrm{g} /$ $\mathrm{mL}$. The Petri plates were incubated at $37^{\circ} \mathrm{C}$ for 24 hours. The Zone of inhibition was measured in $\mathrm{mm}$ to estimate the potency of the test compounds.

\section{Results and discussion}

All the compounds SB1-SB10 and BL1-BL10 were synthesized according to Figure 1 and subjected to in-vitro antimicrobial susceptibility testing against Stayphylococcus aureus, Bacillus subtilis, Proteus vulgaris, Escherichia coli, Aspergillus niger and Aspergillus fumigatus strains in order to determine structureactivity relationship taking ampicillin and fluconazole as broadspectrum antibacterial and antifungal standard drugs respectively. The zone of inhibition around the disc against the tested pathogens was determined at $300 \mu \mathrm{g} / \mathrm{mL}$ concentration by disc diffusion assay.

Table 3: Results of the in-vitro antimicrobial susceptibility testing observed in azomethines.

\begin{tabular}{|c|c|c|c|c|c|c|c|}
\hline \multirow{3}{*}{ S.No. } & \multirow{3}{*}{ Comp.Name } & \multicolumn{6}{|c|}{ Diameter of Zone of Inhibition in $\mathrm{mm}$} \\
\hline & & \multicolumn{2}{|c|}{ Fungal strains } & \multicolumn{2}{|c|}{ Gram “+"ve } & \multicolumn{2}{|c|}{ Gram “-"ve } \\
\hline & & A.niger & A. fumigatus & B. subtilis & S. aureus & E. coli & P. vulgaris \\
\hline 1. & SB1 & 15 & 13 & 12 & 13 & 13 & 16 \\
\hline 2. & SB2 & 19 & 18 & 19 & 21 & 20 & 22 \\
\hline 3. & SB3 & 17 & 17 & 16 & 16 & 15 & 20 \\
\hline 4. & SB4 & 17 & 20 & 18 & 24 & 23 & 23 \\
\hline 5. & SB5 & 16 & 18 & 16 & 19 & 17 & 22 \\
\hline 6. & SB6 & 12 & 13 & 13 & 11 & 14 & 12 \\
\hline 7. & SB7 & 19 & 22 & 19 & 20 & 18 & 23 \\
\hline 8. & SB8 & 12 & 16 & 18 & 20 & 19 & 22 \\
\hline 9. & SB9 & 10 & 17 & 16 & 19 & 20 & 21 \\
\hline 10. & SB10 & 11 & 13 & 13 & 14 & 17 & 16 \\
\hline 11. & Amp & - & - & 34 & 33 & 33 & 35 \\
\hline 12. & Fluc & 35 & 36 & - & - & - & - \\
\hline 13. & DMSO & - & - & - & - & - & - \\
\hline
\end{tabular}

$\mathrm{Amp}=$ Ampicillin, Fluc $=$ Fluconazole, $\mathrm{DMSO}=$ Dimethyl sulfoxide Concentration $=300 \mu \mathrm{g} / \mathrm{mL}$

It is clearly evident from Table 3 that azomethine SB4 bearing p-fluoro group exhibited good activity against the microorganisms used in the present study in order $S$. Aureus $>$ E. coli $=P$. vulgaris $>$ A. fumigatus $>$ B. subtilis $>$ A. niger. Moreover this compound shows clear zone of inhibition of $24 \mathrm{~mm}$ (against $S$. Aureus), $23 \mathrm{~mm}$ (against E. coli and $P$. vulgaris), 20mm (against $A$. fumigatus), $18 \mathrm{~mm}$ (against B. subtilis) and $17 \mathrm{~mm}$ (against A. niger).

Compound SB7 (Table 3) bearing p-chloro group exhibited moderate activity against tested microorganisms in order $P$. vulgaris $>$ A. fumigatus $>$ S. aureus $>$ A. niger $=B$. subtilis $>$ E. coli slight lesser than p-fluoro substituted compounds. This compound showed clear zone of inhibition of $23 \mathrm{~mm}$ (against $P$. vulgaris), $22 \mathrm{~mm}$ (against $A$. fumigatus), $20 \mathrm{~mm}$ (S. aureus) $19 \mathrm{~mm}$ (against $A$. niger and B. subtilis) $18 \mathrm{~mm}$ (against E. coli).

Table 4 shows the antimicrobial screening results of $\beta$-lactam derivatives which clearly indicate that compound BL4 (Table 4) bearing p-fluoro group exhibited better activity against the tested microorganisms in order $S$. aureus $>$ P. vulgaris $>$ E. coli $>$ B. subtilis $>$ A. niger $>$ A. fumigatus with clear zone of inhibition of $27 \mathrm{~mm}$ (against $S$. aureus), 26mm (against P. vulgaris), 25mm (against $E$. coli), 23mm (against B. subtilis), 22mm (against $A$. niger) and $20 \mathrm{~mm}$ (against $A$. fumigatus). 
Table 4: Results of the in-vitro antimicrobial susceptibility testing observed in $\beta$-lactams (BL1-BL10).

\begin{tabular}{|c|c|c|c|c|c|c|c|}
\hline \multirow{3}{*}{ S.No. } & \multirow{3}{*}{ Comp.Name } & \multicolumn{6}{|c|}{ Diameter of Zone of Inhibition in $\mathrm{mm}$} \\
\hline & & \multicolumn{2}{|c|}{ Fungal strains } & \multicolumn{2}{|c|}{ Gram “+”ve } & \multicolumn{2}{|c|}{ Gram “-"ve } \\
\hline & & A. niger & A. fumigatus & B. subtilis & S. aureus & E. coli & P. vulgaris \\
\hline 1. & BL1 & 18 & 15 & 17 & 20 & 13 & 19 \\
\hline 2. & BL2 & 19 & 17 & 22 & 21 & 20 & 23 \\
\hline 3. & BL3 & 20 & 19 & 16 & 20 & 16 & 19 \\
\hline 4. & BL4 & 22 & 20 & 23 & 27 & 25 & 26 \\
\hline 5. & BL5 & 17 & 18 & 18 & 20 & 20 & 23 \\
\hline 6. & BL6 & 14 & 17 & 14 & 19 & 15 & 16 \\
\hline 7. & BL7 & 21 & 19 & 22 & 19 & 25 & 20 \\
\hline 8. & BL8 & 18 & 17 & 20 & 20 & 18 & 21 \\
\hline 9. & BL9 & 16 & 18 & 15 & 17 & 14 & 18 \\
\hline 10. & BL10 & 20 & 18 & 20 & 17 & 23 & 19 \\
\hline 11. & Amp & - & - & 41 & 38 & 37 & 42 \\
\hline 12. & Fluc & 39 & 36 & - & - & - & - \\
\hline 13. & DMSO & - & - & - & - & - & - \\
\hline
\end{tabular}

Amp $=$ Ampicillin, Fluc $=$ Fluconazole, DMSO $=$ Dimethylsulphoxide Concentration $=300 \mu \mathrm{g} / \mathrm{mL}$

It is also indicated by Table 4 that compound BL7 bearing p-fluoro group exhibited good activity against the tested microorganisms in order E. coli $>$ B. subtilis $>$ A. niger $>$ P. vulgaris $>A$. fumigatus $>S$. aureus with clear zone of inhibition of $25 \mathrm{~mm}$ (against E. coli), $22 \mathrm{~mm}$ (against $B$. subtilis), $21 \mathrm{~mm}$ (against $A$. niger) $20 \mathrm{~mm}$ (against $P$. vulgaris) $19 \mathrm{~mm}$ (against $S$. aureus and $A$. fumigatus) (Figure 1).

\section{Conclusion}

The study demonstrates that a series of azomethines and novel $\beta$-lactams were synthesized from 3,3'-( (4-formyl-3methoxyphenyl)azanediyl)dipropanenitrile by the condensation with corresponding aromatic amine. Novel $\beta$-lactams were derived by electro cyclization at the imine linkage of azomethines and were evaluated as bioactive agents. The newly synthesized compounds exhibited promising antimicrobial activity using disc diffusion method. The studies showed significant activity as compared to standard. It can be concluded that this class of compounds holds promise towards good active leads in medicinal chemistry. These efforts creates opening of a new interest in this class of compounds in the field of antimicrobials.

\section{Acknowledgement}

Authors are grateful to Defence Research Development Establishment (DRDE) and ITM University, Gwalior for spectral analysis.

\section{References}

1. (2013) Antibiotic Resistance Threats in the United States, 2013. Antibiotic/Antimicrobial resistance: CDC Threat Report, Atlanta, USA.

2. Ferari MB, Biscegli F, Pelosi G, Tarasconi P, Albertini R, et al. (2004) Synthesis, characterization and biological activity of copper complexes with pyridoxal thiosemicarbazone derivatives. X-ray crystal structure of three dimeric complexes. J Inorg Biochem 98(2): 301-312.

3. Yuksektepe C, Calistcan N, Yilmaz I, Cukurovali A (2006) 2-\{[4-(3-Mesityl3-methylcyclo butyl)thia $\neg$ zol-2-yl]hydrazono $\}$-1,2-diาphenyl $\urcorner$ ethanol ethanol solvate. Acta Cryst E 62: 2762-2764.

4. Raman N, Muthuraj V, Ravichandran S, Kulandaisamy A (2003) Synthesis, characterization and electrochemical behavior of $\mathrm{Cu}(\mathrm{II}), \mathrm{Co}(\mathrm{II}), \mathrm{Ni}(\mathrm{II})$ and $\mathrm{Zn}(\mathrm{II})$ complexes derived from acetylacetone and $\mathrm{p}$-anisidine and their antimicrobial activity. J Chemical Sci 115(3): 161-167.

5. Jha S, Soni Pradeep K, Bansal R, Halve AK (2017) Synthesis, characterization and evaluation of antifungal potential of new azomethines derived from 3-methoxy-4- substituted benzaldehydes and sulfonamides. Ind J Heterocyclic Chem 27(2): 211-216.

6. Deshmukh P, Soni Pradeep K, Bansal R, Halve AK (2017) Synthesis and characterization of some new biologically active imines derived from 3-methoxy-4-acetyloxy-benzaldehyde and 3-methoxy-4-p-toluenesulphonyloxy-5-allyl-benzaldehyde. Int J Current Research 9(01): 44650-44654.

7. Iqbal A, Siddiqui HL Ashraf CM, Ahmad M, Weaver GW (2007) Synthesis, characterization and antibacterial activity of azomethine derivatives derived from 2-formylphenoxyacetic Acid. Molecules 12(2): 245-254.

8. Jarrahpour A, Khalili D, Clerq ED, Salmi C, Brunel JM (2007) Synthesis, antibacterial, antifungal and antiviral activity evaluation of some new 
bis-Schiff bases of isatin and their derivatives. Molecules 12(8): 17201730.

9. Hegazy WH (2012) Synthesis of organometallic-based biologically active compounds: In vitro antibacterial and antifungal of asymmetric ferrocene-derived Schiff-bases chelates. Int Res J Pure Appl Chem 2(3): 170-182.

10. Mathew B, Vakketh SS, Kumar SS (2010) Synthesis, molecular properties and anthelmintic activity of some Schiff bases of 1,3,4-thiadiazole derivatives. Der Pharma Chemica 2(5): 337-343.

11. Omar TN (2007) Synthesis of Schiff bases of benzaldehyde and salicylaldehyde as anti-inflammatory agents. Iraqi J Pharm Sci 16(2): $5-11$.

12. Vazzana I, Terranova E, Mattioli F, Sparatore F (2004) Aromatic Schiff bases and 2,3-disubsti tuted-1,3-thiazolidin-4-one derivatives as antiinflammatory agents. Arkivoc 1(5): 364-374.

13. Sondhi SM, Singh N, Kumar A, Lozach O, Meijer L (2006) Synthesis, antiinflammatory, analgesic and kinase (CDK-1, CDK-5 and GSK-3) inhibition activity evaluation of benzimidazole/benzoxazole derivatives and some Schiff's bases. Bioorg Med Chem 14(11): 3758-3765.

14. Das A, Trousdale MD, Ren S, Lien EJ (1999) Inhibition of herpes simplex virus type- 1 and adenovirus type- 5 by heterocyclic Schiff bases of aminohydroxyguanidine tosylate. Antiviral Res 44(3): 201-208.

15. Melnyk P, Leroun V, Sergheraert C, Grellier P (2006) Design, synthesis and in vitro antimalarial activity of an acylhydrazone library. Bioorg Med Chem Lett 16(1): 31-35.

16. Przybylski P, Huczynski A, Pyta K, Brzezinski B, Bartl F (2009) Biological properties of Schiff bases and azo derivatives of phenols. Curr Org Chem 13(2): 124-148.

17. Manhas MS, Sharma SD, Amin SG (1997) Synthesis and anti-inflammatory activity of some substituted thienopyrimidones. J Med Chem 15(1): 106107.

18. Singh GS, Mbukwa Pheko T (2007) Synthesis and antimicrobial activity of new 2-azetidinones from $\mathrm{N}$-(salicylidene)amines and 2-diazo-1,2diarylethanones. ARKIVOC (ix): 80-90.

19. Gross ME, Giron KP, Septimus JD, Mason EO, Musher DM (1995) Antimicrobial activities of beta-lactam antibiotics and gentamicin against penicillin-susceptible and penicillin-resistant pneumococci. Antimicrobial Agents Chemotherapy 39(5): 1166-1168.

20. Solapure S, Neela Dinesh N, Shandil R, Ramachandran V, Sharma S, et al. (2013) In vitro and in vivo efficacy of $\beta$-lactams against replicating and slowly growing/non-replicating mycobacterium tuberculosis. Antimicrob Agents Chemother 57(6): 2506-2510.

21. Genç H, Kalin R, Koksal Z, Sadeghian N, Kocyigit UM, et al. (2016) Discovery of potent carbonic anhydrase and acetylcholinesterase inhibitors: 2-aminoindan $\beta$-lactam derivatives. Int J Mol Sci 17(10): 1736.

22. Vijay Kumar MMJ, Yogananda R, Snehalatha, Shameer H, Jayachandran E, et al. (2009) Synthesis and characterization of novel N-substituted-3chloro-2-azetidinones as potential anticonvulsant agents. J Biomed Sci Res 1(1): 1-10.

23. Vijay Kumar MMJ, Nagaraja TS, Shameer H, Jayachandran E, Sreenivasa GM (2009) N-Substituted-3-chloro-2-azetidinones: Synthesis and characterization of new novel anti-inflammatory agents. J Pharm Sci Res 1(2): 83-92.

24.Sujani C, Radhika K, Rajasekhar KK, Shankarananth V (2015) Synthesis, characterization and anthelminthic activity of some novel 1,4-Disubstituted azetidinones. Int J Novel Trends Pharmaceut Sci 5(4): $135-142$

25. Goel RK Mahajan MP, Kulkarni SK (2004) Evaluation of antihyperglycemic activity of some novel monocyclic beta lactams. J Pharm Pharm Sci 7(1): 80-83.

26. Deshmukh ARAS, Bhawal BM, Krishnaswamy D, Govande DV, Shinkre BA, et al. (2004) Azetidin-2-ones, synthon for biologically important compounds. Curr Med Chem 11(14): 1889-1920

27. Soni Pradeep K, Bansal R, Halve AK, Parihar JS (2017) Synthesis, characterization and antimicrobial activities of some novel 2-azetidinones derived from cyanoethyl tertiary amino benzaldehydes. Am J PharmTech Res 7(1): 434-444.

28. Arora K, Sharma M, Sharma KP (2011) Synthesis and characterization of Schiff bases coordination compounds of Lanthanide (III) perchlorates. Asian J Chem 23(2): 519-521.

29. Arora K, Sharma KP (2002) Studies on high-coordination complexes of dioxouranium (vi) with a Schiff base. Synth React Inorg Met-Org Chem 32(5): 913-922.

30. Mustafa IM, Hapipah MA, Abdulla MA, Robinson T, Ward TR (2009) Synthesis, structural characterization, and anti-ulcerogenic activity of Schiff base ligands derived from tryptamine and 5-chloro, 5-nitro, 3,5-ditertiarybutyl salicylaldehyde and their nickel (II), copper (II), and zinc (II) complexes. Polyhedron 28(18): 3993-3998. 